\title{
Article \\ Fast and Reliable Determination of Phthalic Acid Esters in the Blood of Marine Turtles by Means of Solid Phase Extraction Coupled with Gas Chromatography-Ion Trap/Mass Spectrometry
}

\author{
Ivan Notardonato ${ }^{1}$, Cristina Di Fiore ${ }^{1}$, Alessia Iannone ${ }^{1}$, Mario Vincenzo Russo ${ }^{1} \mathbb{D}$, Monica Francesca Blasi ${ }^{2,3,4}$, \\ Gabriele Favero $^{2}$ (D), Daniela Mattei ${ }^{3}$, Carmela Protano ${ }^{5}$ (D), Matteo Vitali ${ }^{5}$ (D) and Pasquale Avino ${ }^{1, *(D)}$ \\ 1 Department of Agriculture, Environmental and Food Sciences, University of Molise, \\ I-86100 Campobasso, Italy; ivan.notardonato@unimol.it (I.N.); c.difiore@studenti.unimol.it (C.D.F.); \\ a.iannone2@studenti.unimol.it (A.I.); mvrusso@unimol.it (M.V.R.) \\ 2 Department of Chemistry and Technologies of Drug, University of Rome "La Sapienza", I-00185 Rome, Italy; \\ blasimf@yahoo.com (M.F.B.); gabriele.favero@uniroma1.it (G.F.) \\ 3 Department of Environment and Health, Italian National Health Institute, I-00161 Rome, Italy; \\ daniela.mattei@iss.it \\ 4 Filicudi Wildlife Conservation, Stimpagnato Filicudi, I-98050 Lipari, Italy \\ check for \\ updates \\ 5 Department of Public Health and Infectious Diseases, University of Rome La Sapienza, I-00185 Rome, Italy; \\ carmela.protano@uniroma1.it (C.P.); matteo.vitali@uniroma1.it (M.V.) \\ * Correspondence: avino@unimol.it; Tel.: +39-0874-404-634
}

Citation: Notardonato, I.; Di Fiore, C.; Iannone, A.; Russo, M.V.; Blasi, M.F.; Favero, G.; Mattei, D.; Protano, C.; Vitali, M.; Avino, P. Fast and Reliable Determination of Phthalic Acid Esters in the Blood of Marine Turtles by Means of Solid Phase Extraction Coupled with Gas Chromatography-Ion Trap/Mass Spectrometry. Toxics 2021, 9, 279. https://doi.org/10.3390/toxics9110279

Academic Editors: Lidia Caporossi and Maria Marino

Received: 11 September 2021

Accepted: 19 October 2021

Published: 22 October 2021

Publisher's Note: MDPI stays neutral with regard to jurisdictional claims in published maps and institutional affiliations.

Copyright: () 2021 by the authors. Licensee MDPI, Basel, Switzerland. This article is an open access article distributed under the terms and conditions of the Creative Commons Attribution (CC BY) license (https:// creativecommons.org/licenses/by/ $4.0 /)$.

\begin{abstract}
The presence of phthalic acid esters (PAEs) in marine environments is an important issue. These chemicals are able to affect marine organisms, particularly marine turtles, and to act as endocrine disrupters. In this paper, for the first time, a simple and reproducible analytical method based on solid-phase extraction (SPE) coupled with gas chromatography-ion trap/mass spectrometry (GC-IT/MS) was developed for the extraction of phthalates from the blood of marine turtles. The extraction was obtained by using $\mathrm{C}_{18}$ phthalates-free as the stationary phase. In order to individuate the best working conditions for the extraction, the adsorption isotherms and breakthrough curves were studied. The overall analytical methodology was validated in terms of limit of detection (LOD, 0.08-0.6 $\mathrm{ng} \mathrm{mL}^{-1}$ ), limit of quantification (LOQ, $0.4-0.8 \mathrm{ng} \mathrm{mL}^{-1}$ ), and correlation coefficients ( $>0.9933)$. By using this procedure, percentage recoveries ranging from 89 to $103 \%$ were achieved. The precision parameters (intra-day and inter-day) were studied, and the obtained values were smaller than $12.5 \%$. These data confirm the goodness of the proposed analytical methodology, which is applied to real samples.
\end{abstract}

Keywords: PAEs; blood; marine turtles; Caretta caretta; pollution; SPE; GC-IT/MS

\section{Introduction}

Currently, marine environmental pollution by phthalic acid esters (PAEs) is a crucial topic, which is garnering global scientific attention. PAEs are regarded as the most ubiquitous chemicals, used in several industrial sectors for enhancing the properties of polymers, such as flexibility, softness, and workability [1,2]. Generally, finished plastic products contain $20-40 \%(w / w)$ PAEs [3]; as these compounds are not chemically bound to plastic polymer, but simply incorporated into it, they can leach from plastic and become widespread in the environment [4]. In this way, they may affect marine organisms, acting as endocrine disrupters (EDCs), and competing with the synthesis of endogenous hormones [5,6]. Several marine organisms are influenced by PAEs, such as plankton, macroalgae, piked dogfish (Squalus acanthias) [7], protozoans, invertebrates, mollusks, crustaceans, and different types of fishes [8]. Recently, PAEs were also detected in tissues of baleen whales [6] and different species of marine turtles in the Mediterranean Sea, an 
area particularly affected by marine plastic litter due to its slow turn over $[9,10]$. The most abundant marine turtle species in the Mediterranean Sea is the loggerhead sea turtle (Caretta caretta, Linnaeus, 1758), which is affected by the anthropogenic plastic debris that reach the sea every year [11]. Generally, this species feed on several prey species among invertebrates and vertebrates in both neritic and oceanic habitats, including those distributed along polluted coastal areas which can, in turn, ingest small plastic debris, accelerating the bioaccumulation of PAEs in marine turtles [12]. Ingestion of plastic particles also occurs since they confuse plastic residues for typical dietary products, by accidental ingestion when consuming natural prey, or from the direct uptake of chemicals from the surrounding seawater [13].

Given the habits and feeding patterns of Caretta caretta, they may be used as biomarkers for exposure to plastic by marine organisms, by analyzing chemicals derived from plastic in the blood [14]. For this purpose, an analytical protocol is necessary for extracting PAEs from an innovative matrix, such as the blood of marine turtles. Blood is chosen for two reasons: (i) given the delicate status of this species, in order to avoid animal stressing, this protocol could be considered a non-invasive sampling method [15]; and (ii), by determining the concentration of PAEs in the blood, it is possible to estimate the exposure of these organisms to these contaminants in live animals, and not only those which are stranded or deceased [16]. According to the data consulted, in fact, many studies on marine turtles were carried out only on turtles found stranded and deceased along Mediterranean coasts, which may significantly limit a correlation between the concentration of PAEs in biological tissues and other environmental parameters [9], and it may not accurately reflect the real health status of turtles [12]. To achieve these goals, for the first time, this paper aims to set up a protocol for extracting and determining PAEs in the blood of marine turtles. The procedure is based on solid-phase extraction (SPE) coupled with a gas chromatography-ion trap/mass spectrometry (GC-IT/MS). SPE was chosen as it allows for the extraction of a wide range of organic analytes from biological matrices (i.e., blood), achieving high extraction efficiencies. Moreover, SPE is more selective in comparison with liquid-liquid extraction (LLE) [17].

Blood is generally used for the evaluation of the health status of organisms (in particular, for humans) by means of analyzing its biochemical parameters, but the normal range of these parameters for turtles is not yet established, and cannot be used. In the literature, it is reported that xenobiotic substances such as polycyclic aromatic hydrocarbons (PAHs), heavy metals [18], and polychlorinated biphenyls (PCBs) [19] were determined in blood of turtles (Green Sea Turtle, C. mydas and Hawksbill Sea Turtle, E. imbricata), using these substances as health biomarkers for these marine organisms. It is hypothesized that these xenobiotic substances might reduce the hatching success of turtles, and determine the onset of new pathologies [12]. Furthermore, since the transport of exogenous substances is realized by means of blood, this matrix may be useful for monitoring chemicals present in turtles. This matrix can thus be used for estimating the health status of marine turtles [20]. Therefore, the analysis of PAEs in blood of marine turtles of the Caretta caretta species may be a way to trace the fate of these xenobiotic substances both in marine organisms, by predicting the load in internal tissues, and in the environment in general [18,19].

In this paper, the authors would like to propose a protocol for determining six PAEs in blood of marine turtles. PAEs investigated in this study are reported in Table 1, namely dimethyl phthalate (DMP), diethyl phthalate (DEP), di-isobutyl phthalate (DiBP), di-nbutyl phthalate (DBP), di-2-(ethylhexyl) phthalate (DEHP) and di- $n$-octyl phthalate (DnOP), whereas Table S1 of the Supplementary Material shows the relative chemical structures. The authors would like to underline that, after a thorough search of the literature, indeed this work is the first study for the detection of phthalates on blood of marine turtles. It should be noted that in this paper the authors chose to consider the di-isobutyl phthalate (DiBP) instead of benzyl butyl phthalate (BBP) due to its important and significant presence in several areas. Furthermore, DiBP is particularly spread in sea water. Since this work focuses on the research of PAEs in the most widespread marine turtle species, the authors 
tried to verify if DiBP is present at significant concentrations in Caretta caretta turtles living in the Mediterranean Sea. This could lead us to understand if this PAE is quite diffused, or not, also in the Mediterranean area [21].

Table 1. Phthalates investigated in this paper, along with their corresponding abbreviations, formulae, molecular weight (MW), and target and qualifier ions.

\begin{tabular}{cccccc}
\hline Phthalate & Abbreviation & Formula & MW & Target Ion & Qualifier Ion \\
\hline Dimethyl Phthalate & DMP & $\mathrm{C}_{10} \mathrm{H}_{10} \mathrm{O}_{4}$ & 194.18 & 163 & 194 \\
Diethyl Phthalate & DEP & $\mathrm{C}_{12} \mathrm{H}_{14} \mathrm{O}_{4}$ & 222.24 & 149 & 177 \\
Di-isobutyl Phthalate & DiBP & $\mathrm{C}_{16} \mathrm{H}_{22} \mathrm{O}_{4}$ & 278.34 & 149 & 205 \\
$n$-Dibutyl Phthalate & DBP & $\mathrm{C}_{16} \mathrm{H}_{22} \mathrm{O}_{4}$ & 278.34 & 149 & 205 \\
Bis-(2-Ethylhexyl) Phthalate & DEHP & $\mathrm{C}_{24} \mathrm{H}_{38} \mathrm{O}_{4}$ & 390.56 & 149 & 167 \\
Di- $n$-octyl Phthalate & DnOP & $\mathrm{C}_{24} \mathrm{H}_{38} \mathrm{O}_{4}$ & 390.56 & 149 & 261 \\
\hline
\end{tabular}

\section{Materials and Methods}

\subsection{Materials and Apparatus}

In this study, DMP, DEP, DiBP, DBP, DEHP and DnOP were investigated in the blood of loggerhead sea turtles. Standards of phthalates were obtained from Sigma-Aldrich (Milan, Italy). Solvents used for the cleaning up and samples extraction such as acetone, $n$-heptane, methanol, methylene chloride, and cyclohexane, were obtained from Merks (Darmstadt, Germany). Phosphoric acid (85\%) was used for the analysis. Phenanthrene was used as Internal Standard (IS), which was also obtained from Merks (Darmstadt, Germany). A solution of the investigated phthalates and the IS were prepared in acetone, with a concentration respectively equal to $500 \mathrm{ng} \mathrm{mL}^{-1}$ and $80 \mathrm{ng} \mathrm{mL}^{-1}$. Moreover, a solution of phosphoric acid/saline solution $\left(9 \mathrm{~g} \mathrm{~L}^{-1}\right)(1+1, v / v)$ (Darmstadt, Germany), necessary for the analysis, was prepared. In addition, it was possible for cross-contamination to occur during the sample collection and storage, as well as during the analytical stages, due to the solvents and environment, thus artificially increasing the measured concentrations [22]. In this study, to prevent cross-contamination, a severe cleaning procedure, deeply described in a previous paper [23], was applied; Figure 1 shows the blank chromatogram, evidencing the absence of any PAE contamination.

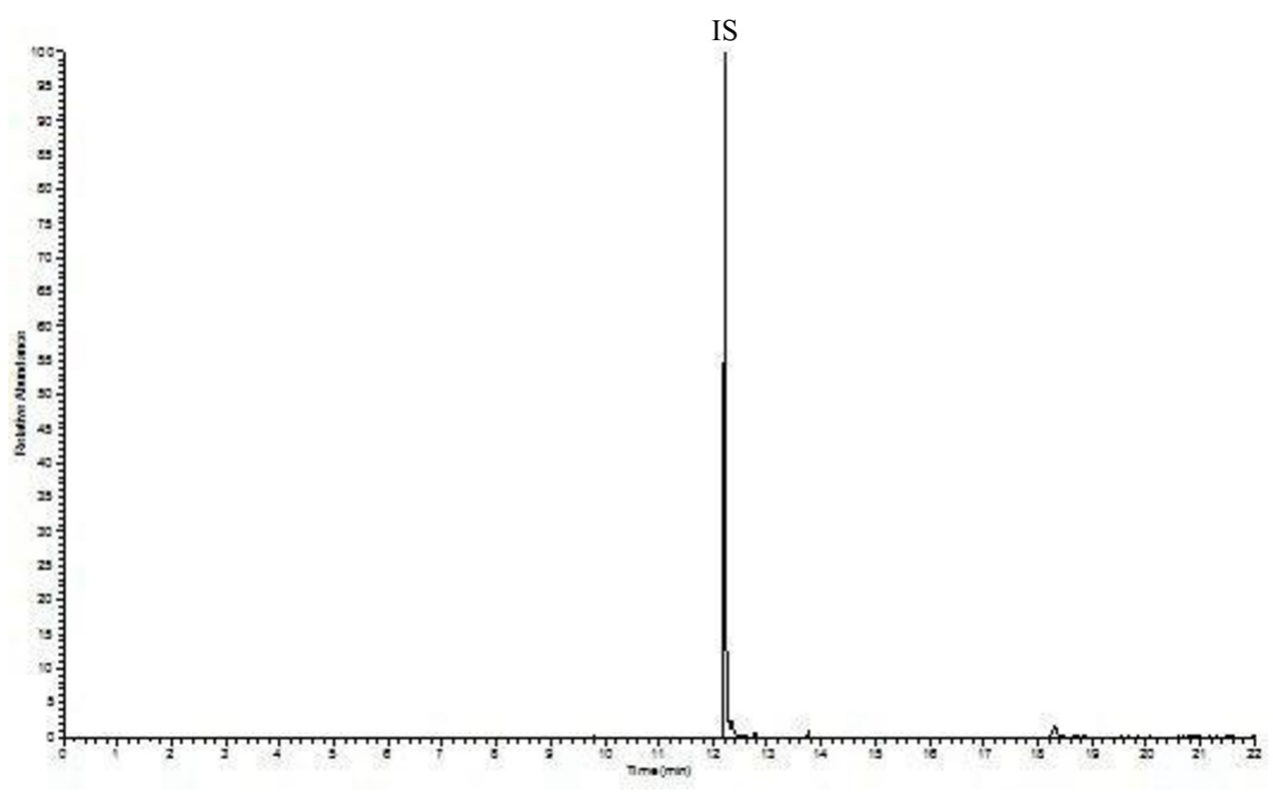

Figure 1. Blank chromatogram evidencing the absence of any PAE contamination in the lab glassware/reagents. The graph reported the relative abundance ( $y$ axis) as function of the time in $\min (x$ axis). For experimental conditions: see text. 
In this study, PAEs were analyzed by means of a Gas Chromatography-Ion Trap Mass Spectrometry (GC-IT/MS) analysis. A gas chromatograph (Thermo Fischer Scientific, Milan, Italy) model Finnigan TraceGC ULTRA equipped with a mass selective detector model (PolarisQ) and an analysis software (Xcalibur) was used. For the analysis, a fused-silica capillary column with a chemically bonded phase (SE-54.5\% phenyl-95\% dimethylpolysiloxane) from Teknokroma was used. The main characteristics were as follows: $30 \mathrm{~m} \times 250 \mu \mathrm{m}$ i.d.; $\mathrm{d}_{\mathrm{f}}$ film thickness, $0.25 \mu \mathrm{m}$; theoretical plate number, $N, 120,000$ for $n$-dodecane at $90{ }^{\circ} \mathrm{C}$; capacity factor, $\mathrm{K}_{1}, 7.3$; optimum linear velocity of carrier gas, hydrogen, $u_{o p t}, 34.5 \mathrm{~cm} \mathrm{~s}^{-1}$; utilization of theoretical efficiency, $95 \%$ was used $[24,25]$. The cartridges used in this study were $100 \mathrm{mg} \mathrm{C}_{18}$ phthalate-free (Chromabond).

\subsection{Sampling}

Loggerhead turtles investigated $(n=4)$ were rescued with detectable diseases or problems in the Aeolian Archipelago waters of the Mediterranean Sea (Sicily, Italy) (Table 2). All of the turtles were hospitalized in the Filicudi Wildlife Conservation First Aid Center for sea turtles and subjected to a physical/clinical health analysis applying the standard procedures [26]. Furthermore, for each turtle, the curved carapace length (CCL), the curved carapace width (CCW), and weight were measured (Table 2).

Table 2. Identification code of turtles investigated in this paper, along with their corresponding rescue areas, curved carapace length (CCL), curved carapace width (CCW), and weight.

\begin{tabular}{ccccc}
\hline $\begin{array}{c}\text { Identification } \\
\text { Code of Turtle }\end{array}$ & Rescue Area & CCL (cm) & CCW (cm) & Weight (kg) \\
\hline A & Sicily & 70.5 & 64.0 & 43.0 \\
B & Sicily & 54.0 & 50.0 & 20.0 \\
C & Sicily & 62.5 & 55.4 & 26.7 \\
D & Sicily & 69.0 & 63.0 & 42.0 \\
\hline
\end{tabular}

Blood ( $2 \mathrm{~mL}$ ) was collected from the cervical sinus at the First Aid Center. After clinical investigation the remaining blood $(1 \mathrm{~mL})$ was placed in heparinized microtubes S-Monovette ${ }^{\circledR}(7.5 \mathrm{~mL} \mathrm{LH}$, code 01.1604 .400 , orange). All the samples were stored at $-20{ }^{\circ} \mathrm{C}$. For blank analysis blood from turtles bred in captivity at the zoological center in Naples was collected and treated in the same way.

\subsection{GC-IT/MS Conditions}

For the gas chromatography analysis, helium was used as gas carrier at linear and constant velocity ( $\overline{\mathrm{u}}$ of $34.5 \mathrm{~cm} \mathrm{~s}^{-1}$ ). $1 \mu \mathrm{L}$ of sample was injected into the programmed temperature vaporizer (PTV) injector in splitless mode. Five seconds after the injection, the vaporizer was heated from $110-280{ }^{\circ} \mathrm{C}$ at $800^{\circ} \mathrm{C} \mathrm{min}-1$, and kept constant for $5 \mathrm{~min}$. After $2 \mathrm{~min}$, the splitter valve was opened. The oven temperature was then programmed from $100-280{ }^{\circ} \mathrm{C}$ at $10{ }^{\circ} \mathrm{C} \mathrm{min}-1$ after injecting. The transfer line temperature was $270{ }^{\circ} \mathrm{C}$. SCAN (electronic impact, EI, at $70 \mathrm{eV}$, mass range from 45-500 amu) and SIM (Selected Ion Monitoring) were used for the acquisition of data.

\subsection{PAE Extraction of Blood from Loggerhead Sea Turtles (Caretta caretta)}

Prior to use, the phthalate-free $\mathrm{C}_{18}$ cartridges were properly conditioned with $3 \mathrm{~mL}$ each of 3 organic solvents with different polarities (acetone, methanol, and $n$-heptane), and rinsed with distilled water. $1 \mathrm{~mL}$ of blood was diluted to $10 \mathrm{~mL}$ with a phosphoric acid/saline solution $(1+1, v / v)$. The solutions obtained were passed through the $\mathrm{C}_{18}$ cartridge phthalates-free at a rate of approximately $5-6 \mathrm{~mL} \mathrm{~min}^{-1}$; the PAEs were then adsorbed by the stationary phase. Before the extraction by using solvent, the cartridge was dried with a gentle airflow for approximately $10 \mathrm{~min}$. The analytes were desorbed from the cartridge with $1 \mathrm{~mL}$ of the methylene chloride by gravity flow. The eluate was collected 
in glass vials, and dried under a gentle nitrogen flow. The analytes were recovered with $200 \mu \mathrm{L}$ of cyclohexane. $1 \mu \mathrm{L}$ was injected into the separation system for the analysis.

\subsection{Adsorption Isotherms}

For the adsorption isotherms, five solutions at different concentrations of PAEs were prepared in the range $50-200 \mathrm{ng} \mathrm{mL}^{-1}$. For the preparation of each solution, $1 \mathrm{~mL}$ of blood was diluted to $100 \mathrm{~mL}$ with the working solution (phosphoric acid/physiological solution, $1+1, v / v)$ in order to obtain the PAEs $/ \mathrm{C}_{18}$ bonded-phase adsorption isotherms at $25^{\circ} \mathrm{C}$. For comparison, adsorbents $(100 \mathrm{mg})$ were added to the working solutions $(100 \mathrm{~mL})$ and gently agitated for $24 \mathrm{~h}$. The obtained suspension was then filtered, and the filtrate was extracted by means of the liquid-liquid extraction technique. The extracts were concentrated under a nitrogen flow. A sample was analyzed by GC-IT/MS.

\subsection{Breakthrough Curves}

In order to individuate the optimum working conditions, breakthrough curves were plotted for PAEs in the working solution on the $\mathrm{C}_{18}$ cartridges used. $1 \mathrm{~mL}$ of blood was diluted to $100 \mathrm{~mL}$ with the working solution. PAEs were subsequently extracted from $10 \mathrm{~mL}$ of the solution previously obtained by means of liquid-liquid extraction technique. The remaining $90 \mathrm{~mL}$ of the solution were passed through the $\mathrm{C}_{18}$ cartridge $(100 \mathrm{mg})$ and collected in aliquots of $10 \mathrm{~mL}$. The liquid-liquid extraction technique was then applied to all of the aliquots obtained in order to extract the analytes.

By analyzing the breakthrough curves, the chosen breakthrough volume was $20 \mathrm{~mL}$, which will be explained later. The cartridges, previously conditioned, were thus enriched with $20 \mathrm{~mL}$ of the solution containing blood from turtles and the phosphoric acid/physiological solution $(1+1, v / v)$. The samples, obtained from the working solution, were then shaken for approximately $2-3 \mathrm{~min}$. After shaking, they were transferred into a glass vessel, which was connected to the $C_{18}$ cartridge. The flow rate $\left(5-6 \mathrm{~mL} \mathrm{~min}^{-1}\right)$ was regulated and controlled by means of a vacuum pump (Vacuubrand, Westheim, Germany).

\subsection{Study of the Extraction Solvent}

An important factor pursued in this study was the choice of the best extraction solvent of PAEs from the $\mathrm{C}_{18}$ cartridge. The cartridges were enriched with $20 \mathrm{~mL}$ of the working solution spiked with $50 \mathrm{ppb}$ of PAEs, and several solvents were tested: $n$-heptane, acetone, methanol, and methylene chloride. Before each extraction using the investigated solvent, the $\mathrm{C}_{18}$ cartridge was air-dried for approximately $5 \mathrm{~min}$ in order to remove the residual water. The adsorbed PAEs were then eluted by using organic solvent at approximately 2-3 $\mathrm{mL} \mathrm{min}^{-1}$ through the cartridge.

In order to validate the extracting solvent, the operation was carried out by adding to the working solution two different concentrations of PAEs, respectively $10 \mathrm{ng} \mathrm{mL}^{-1}$ and $100 \mathrm{ng} \mathrm{mL}^{-1}$. In both cases, the recoveries were in line with the recoveries of the working solution spiked with $50 \mathrm{ng} \mathrm{mL} \mathrm{mL}^{-1}$ concentration of PAEs. Figure 2 shows the GC-IT/MS chromatograms of both (a) the PAEs standard solution, and (b) that obtained by blood samples spiked with $75 \mathrm{ng} \mathrm{mL}^{-1}$.

\subsection{Calibration Graphs}

The calibration curves were obtained by plotting the ratio Area of the peak of each phthalate/Area of Internal Standard vs. concentration. For the construction of the calibration curves, solutions of known and increasing concentration were prepared. In this study 5 points were chosen for the construction of the calibration curves from $10-100 \mathrm{ng} \mathrm{mL}^{-1}$. All solutions were prepared from the same starting solution $\left(500 \mathrm{ng} \mathrm{mL}^{-1}\right)$. In each of the solutions the internal standard $(4 \mu \mathrm{L})$ was added. $1 \mu \mathrm{L}$ of each solution was injected into the CG-IT/MS. 


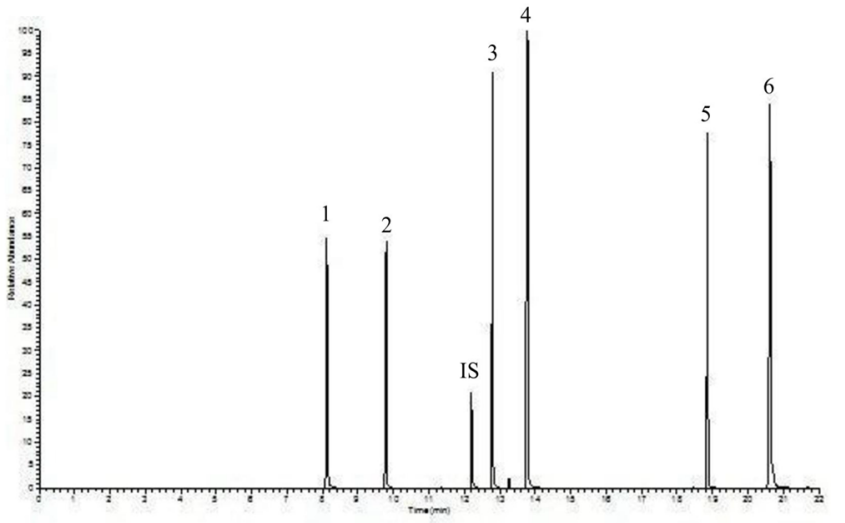

(a)

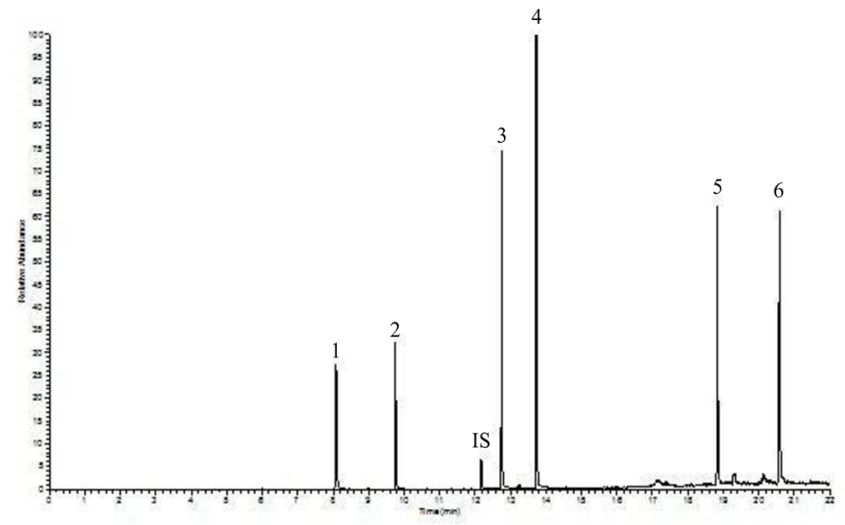

(b)

Figure 2. GC-IT/MS chromatograms of (a) PAEs standard solution, and (b) turtle blood sample spiked with a PAE solution at $75 \mathrm{ng} \mathrm{mL}^{-1}$. The graph reported the relative abundance (y axis) as a function of the time in min ( $x$ axis). Peaks: 1 -DMP; 2-DEP; 3-DiBP; 4-DBP; 5-DEHP; 6-DnOP; IS (Internal Standard)—phenanthrene. For acronyms: see Table 1. For experimental conditions: see text.

\subsection{Analysis of PAEs in Blood Samples}

Before performing the SPE procedure, $1 \mathrm{~mL}$ of blood was spiked with $50 \mathrm{ppb}$ of PAEs. This solution was then diluted to $10 \mathrm{~mL}$ with the working solution. The PAEs were extracted from the initial working solution by means of a liquid-liquid extraction technique proposed by Eckert et al. [27]. This step was essential for confirming the presence of phthalates in the initial solution.

An aliquot of $1 \mathrm{~mL}$ of blood was diluted to a $100 \mathrm{~mL}$ with a solution of aqueous phosphoric acid/physiological solution $(1+1, v / v)$, containing PAEs and the Internal Standard (IS). This solution was extracted thrice with $10 \mathrm{~mL}$ of $n$-heptane. The apolar phase was then collected and placed inside a glass container. Subsequently, the solution was dried under a gentle nitrogen flow and recovered with $250 \mu \mathrm{L}$ of methanol. Finally, $1 \mu \mathrm{L}$ of this solution was injected into the separation system.

\section{Results and Discussion}

\subsection{Evaluation of the Analytical Methodology}

The main purpose of this paper was to develop a method for the extraction of plasticizers (i.e., PAEs) from the blood of marine turtles. For this scope, analytical parameters were determined, such as the adsorption isotherms, breakthrough curves, and the best extraction solvent.

The first step was the study of the adsorption isotherms for PAEs and the stationary phase $\left(\mathrm{C}_{18}\right)$, reported in Figure 3.

The isotherm curves showed that the stationary phase $\left(\mathrm{C}_{18}\right)$ was able to significantly adsorb the PAEs at a low concentration, whereas high concentrations were less adsorbed. Furthermore, the lower molecular weight compounds showed a distribution in favor of the stationary phase, whereas the higher molecular weight compounds showed a distribution in favor of the stationary phase only when their concentration was lower. From the reported curves, it is possible to hypothesize that the molecular weight of the compounds influences their behavior.

The second step was the study of the breakthrough curves. The breakthrough curves $\left(C_{i} / C_{o} \times 100\right.$ vs. volume of blood diluted with the working solution) of PAEs are reported in Figure $4 . C_{i} / C_{o}$ is the ratio between the concentration of solute in effluent $\left(C_{i}\right)$ and the concentration of the incoming solute $\left(\mathrm{C}_{\mathrm{o}}\right)$. The theoretical breakthrough volume, extrapolated from the curves, was approximately $30 \mathrm{~mL}$ for all investigated compounds. Generally, $80 \%$ of the theoretical volume studied can be used as the experimental breakthrough volume. In addition, considering the importance of the matrix and the limited availability of 
loggerhead sea turtle blood, the chosen experimental volume was $20 \mathrm{~mL}$, which could be used without any losses.

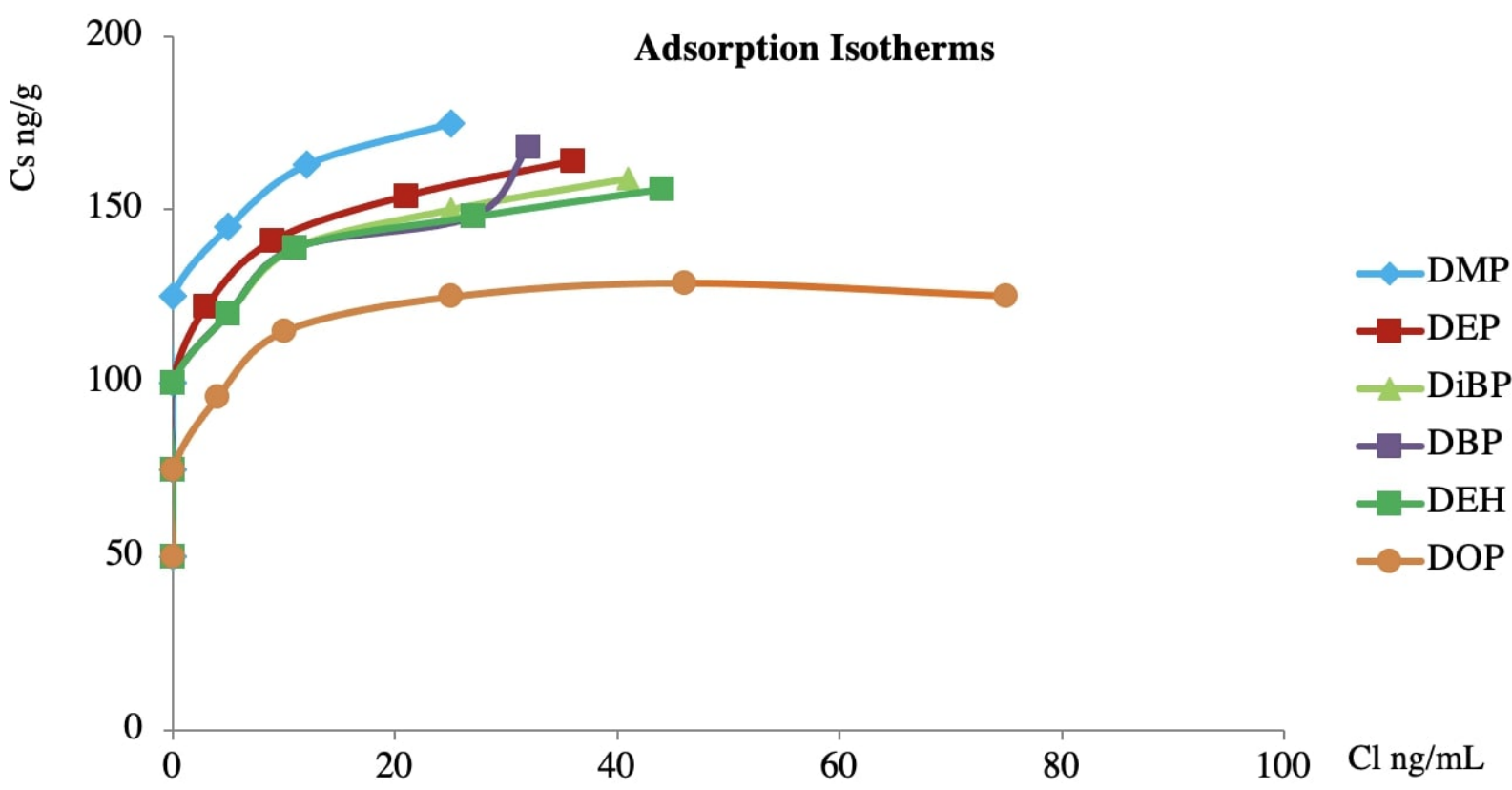

Figure 3. Adsorption isotherm curves at $25^{\circ} \mathrm{C}$ of PAEs between the $\mathrm{C}_{18}$ adsorbent and working solution.

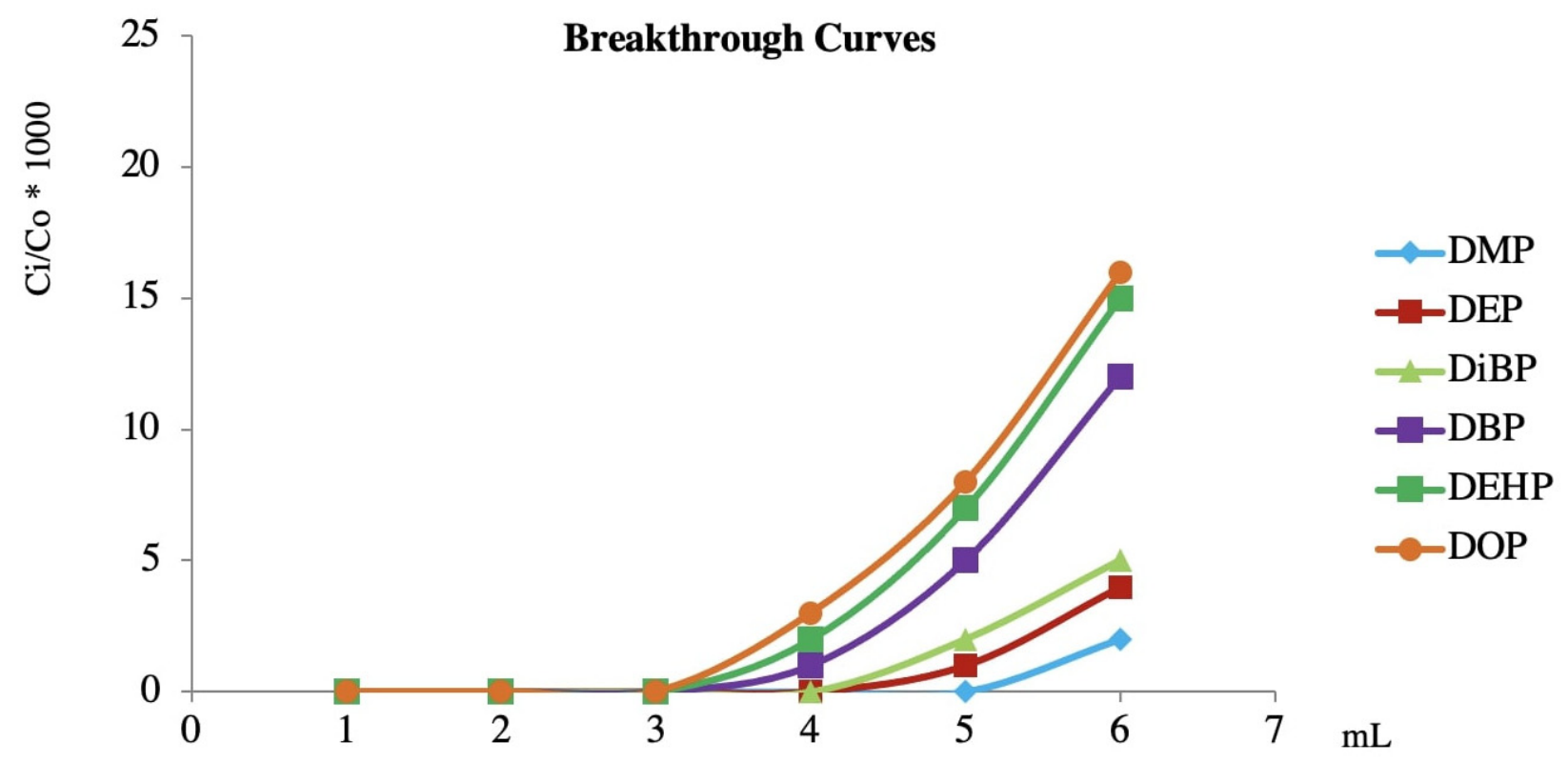

Figure 4. Breakthrough curves for the PAEs on the $C_{18}$ cartridge $(100 \mathrm{mg})$.

The choice of the best extraction solvent of PAEs from the $\mathrm{C}_{18}$ stationary phase was an incredibly important step in this protocol. The extraction solvent had to show high extraction efficiency for the target molecules. For this reason, four solvents were considered. The percentage recoveries obtained through use of the investigated solvents are shown in Table 3. All solvents were tested on $1 \mathrm{~mL}$ fractions for a total of $4 \mathrm{~mL}$ for each solvent. 
Table 3. Mean recoveries (\%), along with standard deviation of the seven investigated PAEs from the $\mathrm{C}_{18}$ cartridge by means of different organic solvents. For acronyms: see Table 1.

\begin{tabular}{ccccccc}
\hline Solvent & & \multicolumn{4}{c}{ Recovery $\left(\mathbf{\%} \pm \mathbf{s . d}^{\mathbf{1}}\right)$} \\
& DMP & DEP & DiBP & DBP & DEHP & DnOP \\
\hline Acetone & $52.2 \pm 5.3$ & $57.0 \pm 6.2$ & $42.5 \pm 4.6$ & $31.3 \pm 6.8$ & $22.6 \pm 8.9$ & $32.4 \pm 9.4$ \\
Methanol & $45.6 \pm 6.7$ & $41.4 \pm 7.3$ & $28.4 \pm 6.8$ & $25.5 \pm 8.4$ & $37.0 \pm 9.3$ & $51.9 \pm 8.8$ \\
n-Heptane & $69.2 \pm 4.2$ & $76.3 \pm 3.7$ & $63.2 \pm 5.1$ & $67.2 \pm 5.7$ & $71.2 \pm 4.8$ & $63.9 \pm 6.4$ \\
Methylene chloride & $96.5 \pm 4.9$ & $97.8 \pm 5.1$ & $89.5 \pm 9.2$ & $103.1 \pm 8.3$ & $99.4 \pm 7.4$ & $92.2 \pm 5.3$ \\
\hline
\end{tabular}

\footnotetext{
${ }^{1}$ s.d.: standard deviation.
}

The reported recoveries were obtained by using four different extraction solvents, characterized by different polarities. Acetone and methanol showed scarce recoveries of PAEs, respectively $22-57 \%$ and $25-52 \%$. $n$-Heptane, by contrast, was able to provide acceptable recoveries, between 63 and $76 \%$. The best recoveries were obtained by using methylene chloride, between 89 and $103 \%$. For this reason, good recoveries were obtained by using an apolar solvent, whereas through the use of a polar solvent, the PAE recoveries were not considered analytically significant. Due to the scarcity of blood samples available, three replicates were carried out for the determination of the percentage recoveries only for the solvent which showed the highest recoveries.

\subsection{GC-IT/MS Method Validation}

For the validation of the analytical method, different analytical parameters, such as limit of detection (LOD), limit of quantification (LOQ), calibration data, percentage recoveries, and method reproducibility were studied; in particular, LODs and LOQs, ranging between $0.08-0.6 \mathrm{ng} \mathrm{mL}^{-1}$ and $0.4-0.8 \mathrm{ng} \mathrm{mL}^{-1}$, respectively, and calibration data, are showed in Table 4.

Table 4. Analytical parameters studied in the range 1-500 $\mathrm{ng} \mathrm{mL}^{-1}$ by means of GC-IT/MS: correlation coefficients $\left(R^{2}\right)$, limit of detection (LOD), limit of quantification (LOQ), and percentage recoveries of spiked samples at two different concentrations for each PAE investigated in this study.

\begin{tabular}{cccccc}
\hline PAE & $\mathbf{R}^{\mathbf{2}}$ & LOD & LOQ & Recovery & Inter-Day \\
\hline & & $\left.\mathbf{( n g ~ m L}^{-\mathbf{1}}\right)$ & $\left.\mathbf{( n g ~ m L}^{-\mathbf{1}}\right)$ & Low conc. ${ }^{\mathbf{1}}$ & High conc. $^{\mathbf{2}}$ \\
\hline DMP & 0.9989 & 0.6 & 0.8 & $91.4 \pm 4.9$ & $94.8 \pm 5.1$ \\
DEP & 0.9985 & 0.3 & 0.8 & $94.1 \pm 6.0$ & $92.5 \pm 5.8$ \\
DiBP & 0.9971 & 0.1 & 0.7 & $96.8 \pm 7.3$ & $99.5 \pm 9.3$ \\
DBP & 0.9965 & 0.08 & 0.7 & $99.7 \pm 9.2$ & $102.5 \pm 7.4$ \\
DEHP & 0.9933 & 0.08 & 0.4 & $96.3 \pm 7.6$ & $93.9 \pm 8.1$ \\
DnOP & 0.9958 & 0.1 & 0.4 & $93.1 \pm 5.4$ & $90.1 \pm 6.2$ \\
\hline
\end{tabular}

${ }_{1}^{1}$ Recoveries (mean $\% \pm$ s.d.) obtained from real sample spiked with $10 \mathrm{ng} \mathrm{mL}^{-1}$ of PAE mixture solution;

${ }^{2}$ recoveries (mean $\% \pm$ s.d.) obtained from real sample spiked with $100 \mathrm{ng} \mathrm{mL}^{-1}$ of PAE mixture solution.

For each PAE investigated, the LODs and LOQs were determined according to Knoll's definition [28]: they were appropriate for determining this group of plasticizers in blood samples. Regarding the calibration data, the linearity of the response for all of the PAEs analyzed was studied in the range of $1-500 \mathrm{ng} \mathrm{mL}^{-1}\left(R^{2}>0.9933\right)$. Precision and accuracy of the analytical methodology were determined, investigating the intra- and inter-day errors. Inter-day data were determined by intra-day error propagation, and for each intra-day three reruns were carried out.

The results, reported in Table 5, showed that the proposed method allowed for the achievement of good percentage recoveries, in a range within $91.3-100.6 \%$, with a relative standard deviation (RSD) smaller than $12.5 \%$. 
Table 5. Inter- and intra-day precision (\%) with relative standard deviation (\%).

\begin{tabular}{ccccccc}
\hline PAE & Intra-Day $\mathbf{1}$ & RSD $^{\mathbf{1}} \mathbf{( \% )}$ & Intra-Day 2 & RSD (\%) & Inter-Day & RSD (\%) \\
\hline DMP & $91.3 \pm 3.1$ & 3.4 & $95.7 \pm 4.0$ & 4.2 & $93.5 \pm 5.1$ & 5.5 \\
DEP & $98.8 \pm 4.0$ & 4.0 & $85.6 \pm 3.4$ & 4.0 & $92.2 \pm 5.2$ & 9.6 \\
DiBP & $100.6 \pm 7.4$ & 7.4 & $95.7 \pm 8.3$ & 8.7 & 11.1 & 11.3 \\
DBP & $96.9 \pm 8.3$ & 8.6 & $104.3 \pm 9.5$ & 9.1 & $100.6 \pm 12.6$ & 12.5 \\
DEHP & $99.6 \pm 5.2$ & 5.2 & $90.1 \pm 6.1$ & 6.8 & $94.9 \pm 8.0$ & $91.3 \pm 5.6$ \\
DnOP & $86.3 \pm 3.6$ & 4.2 & $96.3 \pm 4.3$ & 4.5 & 6.1 \\
\hline
\end{tabular}

${ }^{1}$ RSD: relative standard deviation.

Moreover, as previously mentioned, another goal pursued by the authors was to control cross-contamination, to avoid obtaining artificial results. Cross-contamination with phthalates was a crucial aspect in this study, since the aim of this work was to set up a new method for the extraction of PAEs from an innovative matrix. For this reason, all of the solvents used were subjected to a rigorous procedure, as reported in [23]. The result was a very neat chromatogram, as described above, where PAEs could be easily and successfully identified and determined without issue. Figure 5 shows the chromatogram of a turtle blood sample.

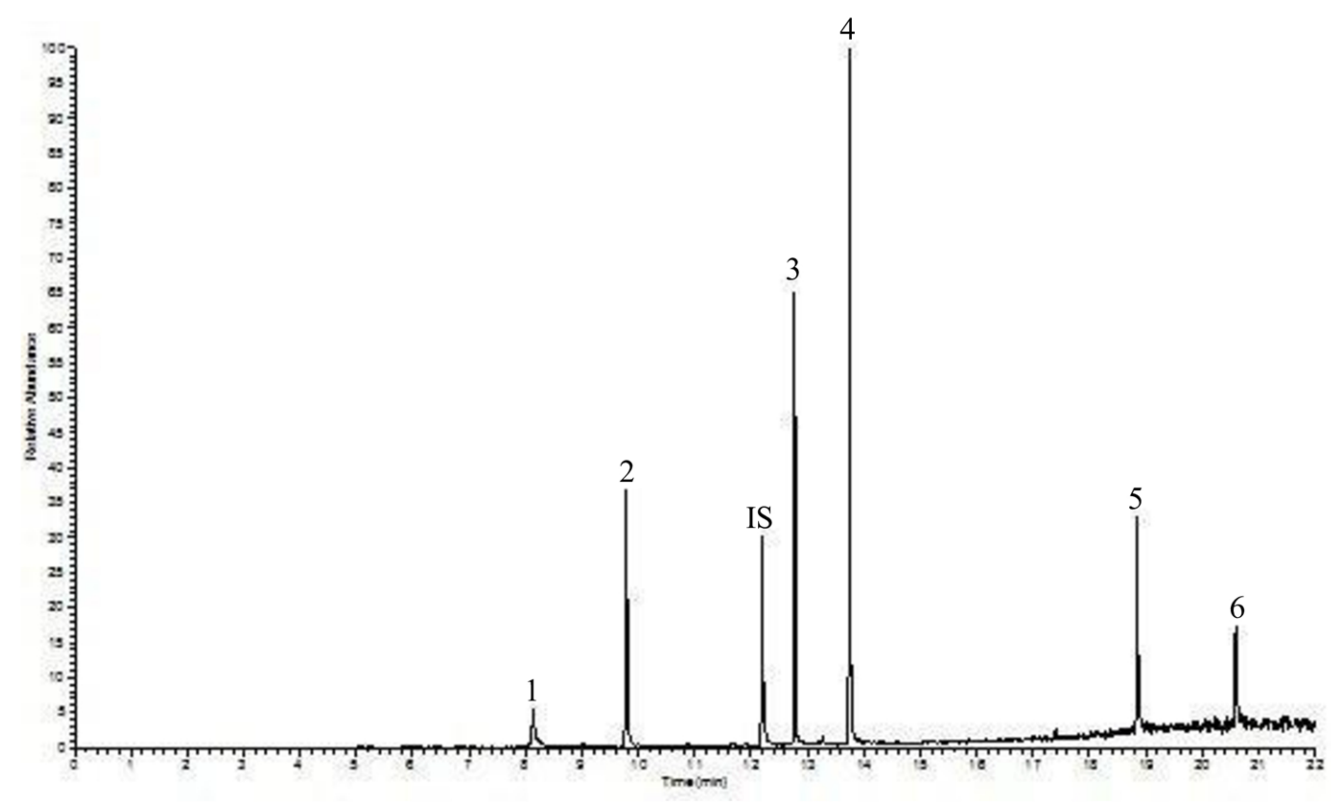

Figure 5. GC-IT/MS chromatogram of PAEs obtained by analyzing a real sample of blood from Caretta caretta turtle. The graph reported the relative abundance ( $y$ axis) as function of the time in min ( $x$ axis). Peaks: 1-DMP; 2-DEP; 3-DiBP; 4-DBP; 5-DEHP; 6-DnOP; IS (Internal Standard)—phenanthrene. For experimental conditions: see text.

\subsection{Similar Studies}

A goal pursued in this paper was to set up a protocol for the extraction of PAEs from blood samples from marine turtles, based on SPE coupled with GC-IT/MS. The Scopus database does not report papers dealing with the determination of PAEs in the blood of marine turtles and of organisms in general (humans included), and this confirms the difficulty and issues in extracting this group of chemicals from a complex biological matrix. For this reason, the authors compared their results with those present in the scientific literature. In particular, the determination of PAHs in the blood of a marine turtle species (C. mydas) is reported. Sinaei et al. [12] determined 16 PAHs in the blood of green sea turtles (C. mydas) by means of liquid chromatography with fluorescence detection, and the only analytical parameter reported was the percentage recovery. The analytical methodology allowed the authors to obtain percentage recoveries higher than $85 \%$. The 
levels of PAHs in that species of marine turtle were significant, ranging between 2.5 and $19 \%$. The authors also compared their results in terms of LODs and LOQs with previously published literature. Ebrahim et al. 2017 [29] determined traces of PAEs in human plasma by means of the dispersive liquid-liquid microextraction, and a gas chromatography with mass spectrometry analysis. For all of the analytes, they obtained an LOD ranging between 1.06 and $1.60 \mathrm{ng} \mathrm{mL}^{-1}$, and values of LOQs ranging between 3.5 and $5.3 \mathrm{ng} \mathrm{mL}^{-1}$, which were higher than those obtained in this study.

It is possible to state that both methods are effective in terms of recoveries, allowing the determination of two different classes of contaminants in the blood of marine turtles. Furthermore, Ehsanpour et al. [18] determined heavy metals in the blood of several species of marine turtle by using atomic absorption spectrophotometry (AAS), demonstrating the contamination of marine turtles by heavy metals in significant concentrations. The authors underlined that their results were in line with those already present in the scientific literature.

\subsection{Application to Real Samples}

The overall method was applied to the blood of turtles rescued in the Mediterranean Sea. The determinations of investigated PAEs were carried out by means of GC-IT/MS, and the results are reported in Table 6.

Table 6. PAEs concentration levels $\left(\mathrm{ng} \mathrm{mL}^{-1}\right)$ determined in the blood of Caretta caretta turtles. For turtle codes: see Table 2. For PAE acronyms: see Table 1.

\begin{tabular}{ccccccc}
\hline Turtle Code & DMP & DEP & DiBP & DBP & DEHP & DnOP \\
\hline A & $<$ LOD & <LOD & $<$ LOD & 6 & $<$ LOD & $<$ LOD \\
B & $<$ LOD & $<$ LOD & 22 & 25 & 40 & 37 \\
C & 14 & 74 & 41 & 57 & 53 & 21 \\
D & $<$ LOD & $<$ LOD & 19 & 26 & 40 & 13 \\
\hline
\end{tabular}

By consulting the obtained data, it is possible to state that the proposed extraction method is reproducible, reliable, sensitive, and allows for a quantitative and qualitative determination of PAEs in the blood of marine turtles. By using the SPE, it was possible to carry out a clean-up of the investigated matrix, facilitating the determination of PAEs by means of the GC-IT/MS.

From the scientific literature, it is known that phthalates are one of a group of organic compounds which are present in aquatic organisms [30]. Different processes, such as leaching and atmospheric deposition, are the main sources of phthalates in aquatic systems [31]. The obtained data confirm the presence of phthalates in Caretta caretta turtles. Looking at the data, DBP is the most commonly found phthalate in Caretta caretta blood, with a concentration ranging between 6 and $57 \mathrm{ng} \mathrm{mL}^{-1}$, which already is on the list of priority compounds of the Convention for the Protection of the Marine Environment of the North-East Atlantic (OSPAR Convention) [32]. Moreover, DiBP, DEHP, and DnOP have been found in three samples of blood, with concentrations ranging between 19 and $41 \mathrm{ng} \mathrm{mL}^{-1}, 40-53 \mathrm{ng} \mathrm{mL}^{-1}$, and 13-37 $\mathrm{ng} \mathrm{mL}^{-1}$, respectively, whereas DMP and DEP have been found in one turtle with a concentration of between 14 and $74 \mathrm{ng} \mathrm{mL}^{-1}$, respectively. Considering these data, it is complex to identify information on the PAEs sources. Environmental conditions such as water salinity and UV radiation may affect the release of additives specifically for each analyte and each type of plastic material. In addition, studies suggested that areas with high levels of turbulence, such as coastlines, might determine a more efficient release of additives from all types of plastic. PVC is capable of leaching the major concentration of phthalates, particularly of DEHP, which is added during PVC production in order to make it soften [31]. For this reason, the significant concentration of DEHP in the blood of turtles may be due to its crucial leaching from PVC plastic litter present in the seawater. In addition, the ability of DEHP to partially solubilize in biological fluids, such as blood and blood plasma, has been demonstrated [33]. DiBP was found in 
three samples at concentrations ranging between 19 and $41 \mathrm{ng} \mathrm{mL}^{-1}$, showing the presence of this PAE in the blood of Caretta caretta. DiBP was, in fact, detected in several areas, and its own presence was particularly important in sea water [21]. Regarding DBP, it is heavily used during the plastic material production, since it is able to add flexibility to plastic. DBP has been found in all analyzed blood samples; similar results are shown in the scientific literature, where the prevalence of DBP and DEHP in Caretta caretta tissues is reported [9]. In one blood sample, only DBP and DEP were found in only one turtle, with a concentration of $6 \mathrm{ng} \mathrm{mL} \mathrm{m}^{-1}$ and $74 \mathrm{ng} \mathrm{mL}^{-1}$, respectively. This could be due to a different diet of the turtle. Loggerhead sea turtles generally consume benthic invertebrates [34], which may ingest hydrophobic contaminants such as PAEs [35]. However, an important variability in terms of prey species in the Mediterranean Sea has been proven [34]. Therefore, the variability in terms of feeding habits may have influenced the concentration of PAEs found. However, the different concentration of phthalates in the blood of the analyzed turtles did not show a significant correlation with the biometric parameters [9]. Furthermore, no information was available regarding the history of the marine animal (e.g., age, area in which it lived, etc.). Considering the potential risk associated with PAEs, a risk assessment is required. The ecological risks deriving from these widespread chemicals impact various marine species. More sensitive fish species are affected by the presence of DiBP, whereas DBP is less dangerous for sensitive fish species. The most important ecological risk derives from the presence of DEHP in the seas, which is capable of determining a high risk for all marine organisms. Since this group of compounds is considered a threat for the health status of marine organisms and the sea in general, further studies will be conducted for an ecological risk assessment in the Mediterranean Sea [36,37].

\section{Conclusions}

The most important aim pursued in this study was to set up a protocol for the extraction of PAEs in a very sensitive matrix, i.e., blood. Even if blood is a well investigated matrix, an analytical procedure for analyzing PAEs in this matrix is not yet present, due to difficulties related both to the biological matrix and to the compounds, which causes difficulties in its analysis. The extracting protocol proposed by the authors would be optimal for a sensitive and reproducible analysis of PAEs in the blood of marine turtles. The protocol allowed for the determination of seven widespread PEAs with reduced analysis times and in the absence of a matrix effect. By using SPE, the obtained LODs and LOQs were between $0.08-0.6 \mathrm{ng} \mathrm{mL}^{-1}$, and a recovery between 89 and $103 \%$ was achieved, which was in line with those reported in similar studies published in the scientific literature [38]. This method is therefore useful and interesting for a rapid and non-invasive determination of PAEs in live marine turtles, and is also an inexpensive procedure. By applying this procedure, the obtained results showed the presence of PAEs in the blood of marine turtles, with a concentration raging between 6 and $74 \mathrm{ng} \mathrm{mL} \mathrm{m}^{-1}$ of blood. In addition, the authors hypothesize that, by using this extracting protocol, it will be possible to carry out the extraction of these chemicals from the blood of other species of marine turtles (and other marine organisms) in order to implement the scientific literature.

Supplementary Materials: The following are available online at https: / www.mdpi.com/article/ 10.3390/toxics9110279/s1, Table S1: Phthalates (PAEs) investigated in this paper, with their corresponding abbreviations, chemical structure, CAS number, chemical formula, molecular weight (MW) and Selected Ion Monitoring (SIM).

Author Contributions: Conceptualization, P.A.; Data curation, M.F.B. and D.M.; Formal analysis, I.N., C.D.F. and A.I.; Funding acquisition, P.A.; Investigation, M.F.B., C.D.F. and A.I.; Methodology, M.V.R.; Project administration, M.F.B. and G.F.; Resources, I.N. and P.A.; Software, C.P. and M.V.; Supervision, P.A.; Validation, P.A.; Visualization, I.N., C.D.F., M.F.B. and P.A.; Roles/Writing-original draft, C.D.F. and I.N.; Writing-review \& editing: M.F.B. and P.A. All authors have read and agreed to the published version of the manuscript.

Funding: This research received no external funding. 
Institutional Review Board Statement: Authorizations for loggerhead turtle rescue and first aid were provided by the Italian Ministry of Environment (prot. n. 0001735, 2 February 2010; prot. n. 0006876, 25 January 2013; prot. n. 0011903, 1 June 2016; prot. n. 0009981, 1 February 2021), and by the Sicilian Region (prot. n. 17813, 2 March 2020).

Informed Consent Statement: Not applicable.

Acknowledgments: Logistic and support for samples collection was provided by Filicudi Wildlife Conservation.

Conflicts of Interest: The authors declare that they have no known competing financial interests or personal relationships that could have appeared to influence the work reported in this paper.

\section{References}

1. Wang, J.; Luo, Y.; Teng, Y.; Ma, M.; Christie, P.; Li, Z. Soil contamination by phthalate esters in Chinese intensive vegetable production systems with different modes of use of plastic film. Environ. Pollut. 2013, 180, 265-273. [CrossRef] [PubMed]

2. Notardonato, I.; Protano, C.; Vitali, M.; Avino, P. Phthalates and Bisphenol-A determination and release from different beverage plastic containers by dispersive liquid-liquid microextraction and GC-IT/MS analysis. Food Anal. Methods 2019, 12, $2562-2571$. [CrossRef]

3. Xie, Q.; Liu, S.; Fan, Y.; Sun, J.; Zhang, X. Determination of phthalate esters in edible oils by use of QuEChERS coupled with ionic-liquid-based dispersive liquid-liquid microextraction before high-performance liquid chromatography. Anal Bioanal. Chem. 2014, 406, 4563-4569. [CrossRef] [PubMed]

4. Arfaeinia, H.; Fazlzadeh, M.; Taghizadeh, F.; Saeedid, R.; Spitze, J.; Dobaradaran, S. Phthalate acid esters (PAEs) accumulation in coastal sediments from regions with different land use configuration along the Persian Gulf. Ecotoxicol. Environ. Saf. 2019, 169, 496-506. [CrossRef] [PubMed]

5. Salvaggio, A.; Tiralongo, F.; Krasakopoulou, E.; Marmara, D.; Giovos, I.; Crupi, R.; Messina, G.; Lombardo, B.M.; Marzullo, A.; Pecoraro, R.; et al. Biomarkers of exposure to chemical contamination in the commercial fish species Lepidopus caudatus (Euphrasen, 1788): A particular focus on plastic additives. Front. Physiol. 2019, 10, 905. [CrossRef] [PubMed]

6. Fossi, M.C.; Panti, C.; Guerranti, C.; Coppola, D.; Giannetti, M.; Marsili, L.; Minutoli, R. Are baleen whales exposed to the threat of microplastics? A case study of the Mediterranean fin whale (Balaenoptera physalus). Mar. Pollut. Bull. 2012, 64, 2374-2379. [CrossRef] [PubMed]

7. Hermabessiere, L.; Dehaut, A.; Paul-Pont, I.; Lacroix, C.; Jezequel, R.; Soudant, P.; Duflos, G. Occurrence and effects of plastic additives on marine environments and organisms: A review. Chemosphere 2017, 182, 781-793. [CrossRef]

8. Saliu, F.; Montano, S.; Lasagni, M.; Galli, P. Biocompatible solid-phase microextraction coupled to liquid chromatography triple quadrupole mass spectrometry analysis for the determination of phthalates in marine invertebrate. J. Chromatogr. A 2020, 1618, 460852. [CrossRef]

9. Savoca, D.; Arculeo, M.; Barreca, S.; Buscemia, S.; Caracappa, S.; Gentile, A.; Persichetti, M.F.; Pace, A. Chasing phthalates in tissues of marine turtles from Mediterranean Sea. Mar. Pollut. Bull. 2018, 127, 165-169. [CrossRef]

10. Paluselli, A.; Fauvelle, V.; Schmidt, N.; Galgani, F.; Net, S.; Sempéré, R. Distribution of phthalates in Marseille Bay (NW Mediterranean Sea). Sci. Total Environ. 2018, 621, 578-587. [CrossRef]

11. Domènech, F.; Aznar, F.J.; Raga, J.A.; Tomas, J. Two decades of monitoring in marine debris ingestion in loggerhead sea turtle, Caretta caretta, from the western Mediterranean. Environ. Pollut. 2019, 244, 367-378. [CrossRef]

12. Sinaei, M.; Zare, R. Polycyclic aromatic hydrocarbons (PAHs) and some biomarkers in the green sea turtles (Chelonia mydas). Mar. Pollut. Bull. 2019, 146, 336-342. [CrossRef]

13. Smith, M.; Love, D.; Rochman, C.M.; Neff, R.A. Microplastics in seafood and the implications for human health. Curr. Environ. Health Rep. 2018, 5, 375-386. [CrossRef]

14. Biamis, C.; O' Driscoll, K.; Hardiman, G. Microplastic toxicity: A review of the role of marine sentinel species in assessing the environmental and public health impacts. Case Stud. Chem. Environ. Eng. 2021, 3, 100073. [CrossRef]

15. Guerranti, C.; Baini, M.; Casini, S.; Focardi, S.E.; Giannetti, M.; Mancusi, C.; Marsili, L.; Perra, G.; Fossi, M.C. Pilot study on levels of chemical contaminants and prophyrins in Caretta caretta from Mediterranean Sea. Mar. Environ. Res. 2014, 100, 33-37. [CrossRef] [PubMed]

16. Camacho, M.; Boada, L.D.; Orós, J.; Calabuig, P.; Zumbado, M.; Luzardo, O.P. Comparative study of polycyclic aromatic hydrocarbons (PAHs) in plasma of Eastern Atlantic juvenile and adult nesting loggerhead sea turtles (Caretta caretta). Mar. Pollut. Bull. 2012, 64, 1974-1980. [CrossRef] [PubMed]

17. Andrade-Eiroa, A.; Canle, M.; Leroy-Cancellieri, V.; Cerdà, V. Solid-phase extraction of organic compounds: A critical review (Part II). Trends Anal. Chem. 2016, 80, 655-667. [CrossRef]

18. Ehsanpour, M.; Afkhami, M.; Khoshnood, R.; Reich, K.J. Determination and maternal transfer of heavy metals $(\mathrm{Cd}, \mathrm{Cu}, \mathrm{Zn}, \mathrm{Pb}$ and $\mathrm{Hg}$ ) in the Hawksbill Sea turtle (Eretmochelys imbricata) from a nesting colony of Qeshm Island, Iran. Bull. Environ. Contam. Toxicol. 2014, 92, 667-673. [CrossRef] 
19. D'Ilio, S.; Mattei, D.; Blasi, M.F.; Alimonti, A.; Bogialli, S. The occurrence of chemical elements and POPs in loggerhead turtles (Caretta caretta): An overview. Mar. Pollut. Bull. 2011, 62, 1606-1615. [CrossRef]

20. Dogruer, G.; Weijs, L.; Tang, J.Y.; Hollert, H.; Kock, M.; Bell, I.; Madden Hof, C.A.; Gaus, C. Effect-based approach for screening of chemical mixtures in whole blood of green turtles from the Great Barrier Reef. Sci. Total Environ. 2018, 612, 321-329. [CrossRef]

21. Wang, L.Y.; Gu, Y.Y.; Zhang, Z.M.; Sun, A.L.; Shi, X.Z.; Chen, J.; Lu, Y. Contaminant occurrence, mobility and ecological risk assessment of phthalate esters in the sediment-water system of the Hangzhou Bay. Sci. Total Environ. 2021, 770, 144705. [CrossRef]

22. Kato, K.; Silva, M.J.; Brock, J.W.Z.; Reidy, J.A.; Malek, N.A.; Hodge, C.C.; Nakazawa, H.; Needham, L.L.; Barr, D.D. Quantitative detection of nine phthalate metabolites in human serum using reversed-phase high-performance liquid chromatographyelectrospray ionization tandem mass spectrometry. J. Anal. Toxicol. 2003, 27, 284-289. [CrossRef]

23. Russo, M.V.; Notardonato, I.; Cinelli, G.; Avino, P. Evaluation of an analytical method for determining phthalate esters in wine samples by solid-phase extraction and gas chromatography coupled with ion-trap mass spectrometer detector. Anal. Bioanal. Chem. 2012, 402, 1373-1381. [CrossRef]

24. Russo, M.V.; Avino, P.; Notardonato, I. Fast analysis of phthalates in freeze-dried baby foods by ultrasound-vortex-assisted liquid-liquid microextraction coupled with gas chromatography-ion trap/mass spectrometry. J. Chromatogr. A 2016, 1474, 1-7. [CrossRef] [PubMed]

25. Cinelli, G.; Avino, P.; Notardonato, I.; Centola, A.; Russo, M.V. Rapid analysis of six phthalate esters in wine by ultrasoundvortex-assisted dispersive liquid-liquid micro-extraction coupled with gas chromatography-flame ionization detector or gas chromatography-ion trap mass spectrometry. Anal. Chim. Acta 2013, 769, 72-78. [CrossRef] [PubMed]

26. Blasi, M.F.; Mattei, D. Seasonal encounter rate, life stages and main threats to the loggerhead sea turtle (Caretta caretta) in the Aeolian Archipelago (southern Thyrrenian Sea). Aquat. Conserv. 2017, 27, 617-630. [CrossRef]

27. Eckert, E.; Müller, J.; Göen, T. Simultaneous determination of polyvinylchloride plasticizers di(2-ethylhexyl) phthalate and tri(2-ethylhexyl) trimellitate and its degradation products in blood by liquid chromatography-tandem mass spectrometry. $J$ Chromatogr. A 2015, 1410, 173-180. [CrossRef]

28. Knoll, J.E. Estimation of the limit of detection in chromatography. J. Chromatogr. Sci. 1985, 23, 422-425. [CrossRef]

29. Ebrahim, K.; Poursafa, P.; Amin, M.M. Development of a simple and valid method for the trace determination of phthalate esters in human plasma using dispersive liquid-liquid microextraction coupled with gas chromatography-mass spectrometry. J. Sep. Sci. 2017, 40, 4403-4410. [CrossRef]

30. Natesan, U. Accumulation of organic pollutants in aquatic organisms from Ennore estuary, Chennai, India. Asian J. Chem. 2012, 25, 2392-2394. [CrossRef]

31. Beltifa, A.; Feriani, A.; Machreki, M.; Ghorbel, A.; Ghazouani, L.; Di Bella, D.; Van Loco, J.; Reyns, T.; Ben Mansour, H. Plasticizers and bisphenol A, in packaged foods sold in the Tunisian markets: Study of their acute in vivo toxicity and their environmental fate. Environ. Sci. Pollut. Res. 2017, 24, 22382-22392. [CrossRef]

32. Suhrhoff, T.J.; Scholz-Böttcher, B.M. Qualitative impact of salinity, UV radiation and turbulence on leaching of organic plastic additives from four common plastics-A lab experiment. Mar. Pollut. Bull. 2016, 102, 84-94. [CrossRef] [PubMed]

33. Jaeger, R.J.; Rubin, R.J. Extraction, localization, and metabolism of di-2-ethylhexyl phthalate from PVC plastic medical devices. Environ. Health Perspect. 1973, 3, 95-102. [CrossRef] [PubMed]

34. Donaton, J.; Durham, K.; Cerrato, R.; Schwerzmann, J.; Thorne, L.H. Long-term changes in loggerhead sea turtle diet indicate shifts in the benthic community associated with warming temperatures. Estuar. Coast. Shelf Sci. 2019, 218, 139-147. [CrossRef]

35. Lee, Y.-S.; Lim, J.-E.; Lee, S.; Moon, H.-B. Phthalates and non-phthalate plasticizers in sediment from Korean coastal waters: Occurrence, spatial distribution, and ecological risks. Mar. Environ. Pollut. 2020, 154, 111119. [CrossRef]

36. Liu, Y.; He, Y.; Zhang, J.D.; Cai, C.Y.; Breider, F.; Tao, S.; Liu, W.X. Distribution, partitioning behavior, and ecological risk assessment of phthalate esters in sediment particle-pore water systems from the main stream of the Haihe River, Northern China. Sci. Total Environ. 2020, 745, 141131. [CrossRef]

37. Sun, C.; Chen, L.; Zhao, S.; Guoa, W.; Lu, W.; Wang, L.; Tang, L.; Li, F.; Zhang, J. Seasonal distribution and ecological risk of phthalate esters in surface water and marine organisms of the Bohai Sea. Mar. Pollut. Bull. 2021, 169, 112449. [CrossRef] [PubMed]

38. Olumayowa, J.O.; Adewuyi, G.O.; Ayede, A.I.; Olayemi, O.; Bello, F.A.; Osamor, J.O. Blood transfusion impact on levels of some phthalate esters in blood, urine and breast milk of some nursing mothers in Ibadan South-Western Nigeria. J. Environ. Anal. Chem. 2021, 101, 702-718. 